\title{
ARTICLE
}

\section{Selective dissolution of halide perovskites as a step towards recycling solar cells}

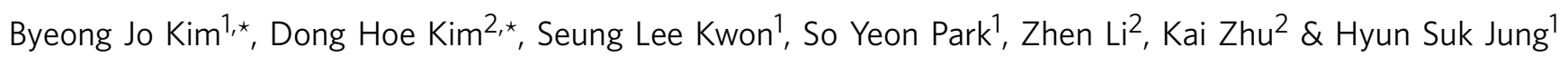

Most research on perovskite solar cells has focused on improving power-conversion efficiency and stability. However, if one could refurbish perovskite solar cells, their stability might not be a critical issue. From the perspective of cost effectiveness, if failed, perovskite solar cells could be collected and recycled; reuse of their gold electrodes and transparent conducting glasses could reduce the price per watt of perovskite photovoltaic modules. Herein, we present a simple and effective method for removing the perovskite layer and reusing the mesoporous $\mathrm{TiO}_{2}$-coated transparent conducting glass substrate via selective dissolution. We find that the perovskite layer can be easily decomposed in polar aprotic solvents because of the reaction between polar aprotic solvents and $\mathrm{Pb}^{2+}$ cations. After 10 cycles of recycling, a mesoporous $\mathrm{TiO}_{2}$-coated transparent conducting glass substrate-based perovskite solar cell still shows a constant power-conversion efficiency, thereby demonstrating the possibility of recycling perovskite solar cells.

\footnotetext{
${ }^{1}$ School of Advanced Materials Science and Engineering, Sungkyunkwan University, Suwon 16419, Korea. ${ }^{2}$ Chemistry and Nanoscience Center, National Renewable Energy Laboratory, Golden, Colorado 80401, USA. * These authors contributed equally to this work. Correspondence and requests for materials should be addressed to H.S.J. (email: hsjung1@skku.edu).
} 
T he advent of perovskite solar cells (PSCs) has led to a change in the paradigm of emerging photovoltaic (PV) technology owing to the significant increase in their power-conversion efficiency within the past 3 years $^{1-3}$. Thus far, the best reported efficiency, achieved by Seok and colleagues, is $22.1 \%$ (ref. 4). This efficiency is comparable to that of other commercialized solar cells, such as multicrystalline $\mathrm{Si}$ (c-Si, 21.3\%), cadmium telluride (CdTe, 22.1\%) and copper indium gallium selenide (CIGS, 22.3\%) solar cells $\mathrm{s}^{4}$. However, to facilitate commercialization of these emerging PVs, various issues must be addressed, such as long-term stability, the need for $\mathrm{Pb}$-free perovskite light-absorbing materials, the economic feasibility of the manufacturing process and an appropriate ecofriendly disposal process for $\mathrm{Pb}$-contained waste. The price of a Si solar module ranges from $\$ 0.6$ to $\$ 1.0$ per Wp (ref. 5), which is significantly higher than the target price of PSCs (lower than $\$ 0.2$ per $\mathrm{Wp}$, see ref. 6). The target price for $\mathrm{PV}$ modules required to achieve grid parity, as determined by the United States Department of Energy, is $\$ 0.5$ per Wp; therefore, the target figure $(\$ 0.2$ per $\mathrm{Wp})$ constitutes a paradigm-changing price ${ }^{7}$.

The competitive price of PSCs results from the low material cost and non-vacuum fabrication process of perovskite light absorbers. However, the relatively high material costs for electron- and hole-transport materials, metallic electrode materials (including gold or silver) and transparent conducting glass (TCG) substrate materials render realization of the target price difficult. For example, at the laboratory scale, the unit price of spiro-MeOTAD (2,2',7,7'-tetrakis[N,N-di(4-methoxyphenyl) amino]-9,9'-spirobifluorene), a widely used hole-transport material, is $\$ 200$ per g (Lumtec). Gold, as a metallic electrode material, and fluorine-doped tin oxide (FTO) glass cost $\$ 40$ per g and approximately $\$ 10$ per $\mathrm{m}^{2}$, respectively. As such, these expensive materials account for $98 \%$ of the costs associated with small, 1 inch $\times 1$ inch square devices. The price of hole-conducting materials is expected to decrease by virtue of new synthesis technologies and large-scale synthesis methods. However, a significant reduction in the prices of gold and FTO glass seems unlikely; in fact, owing to limited mineral resources, their prices may vary significantly depending on global demand.

The recycling of degraded PV modules has been considered as an alternative approach to making PVs economically viable. In particular, improvement of the long-term stability of PSCs is still needed to compete with other types of solar cells, such as c-Si, CdTe and CIGS solar cells, which are being used in commercial PV modules. However, considering the energy payback time (EPBT), which is the time required for a PV module to produce an amount of energy comparable to that consumed during its production, the EPBT of a perovskite PV module is 0.22 years, which is the shortest nominal EPBT compared with all other competitors such as c-Si and CdTe (ref. 8). Therefore, if it were possible to recycle degraded perovskite PV modules, the issues inhibiting the commercialization of perovskite PV modules would be solved, such as their long-term stability, the production of large amounts of $\mathrm{Pb}$-containing waste, the high unit cost of PSCs and the retrieval and reuse of expensive components such as gold, silver and TCG. A shorter payback period of perovskite-based PV modules compared with that of Si-based PV modules could be realized via this process of recycling degraded PSCs.

Therefore, in this paper, we introduce a recycling or repair methodology for PSCs. In this system, trihalide perovskite materials, such as methyl-ammonium lead iodide $\left(\mathrm{CH}_{3} \mathrm{NH}_{3} \mathrm{PbI}_{3}\right.$, abbreviated as MALI) as well as formamidinium lead iodide $\left(\mathrm{HC}\left(\mathrm{NH}_{2}\right)_{2} \mathrm{PbI}_{3}\right.$, abbreviated as FALI $)$ and methyl-ammonium lead bromide $\left(\mathrm{CH}_{3} \mathrm{NH}_{3} \mathrm{PbBr}_{3}\right.$, abbreviated as $\left.\mathrm{MALBr}\right)$ mixed halides (in this study, $(\mathrm{FALI})_{0.85}(\mathrm{MALBr})_{0.15}$ was used), are removed through a selective dissolution process. This process is capable of dissolving PSCs such that the Au electrodes and the $\mathrm{mp}-\mathrm{TiO}_{2}$-coated TCG substrates are separated through the dissolution of the perovskite layers. We find that the recycling of PSCs can be realized based on the removal of trihalide perovskite materials and that a small amount of $\mathrm{Pb}$ residue has a negligible effect on the ability to reuse the $\mathrm{mp}-\mathrm{TiO}_{2}$-coated TCG substrate. The selective dissolution mechanism is attributable to the breaking down of the $\mathrm{PbI}_{6}$ octahedral frame in the trihalide perovskite owing to the reaction between the partially positive $\mathrm{Pb}^{2+}$ ions and a polar aprotic solvent. When the regenerated electron-transport-layer-coated FTO glass (referred to as the $\mathrm{mp}-\mathrm{TiO}_{2}$-coated TCG substrate in this paper) is reused, the original power-conversion efficiency (15\%) is retained over 10 regeneration cycles. This study reveals the potential impact of easily exchangeable PSCs, similar to electric batteries, on the use of PSCs in various applications (for example, as portable power sources in wearable devices and internet-of-things devices).

\section{Results}

Recycling procedure. Figure 1 shows the steps of the recycling process for PSCs. After the deposition and annealing of the electron-transport layer, which is composed (in general) of compact and $\mathrm{mp}-\mathrm{TiO}_{2}$ layers, the MALI light absorber is coated on the substrate. The hole-transport layer (HTL) and gold electrode are then deposited. During recycling, the MALI perovskite and the HTL dissolve when the fabricated solar cell is immersed in a polar aprotic solvent such as dimethylformamide (DMF), $\gamma$-butyrolactone (GBL) or dimethyl sulfoxide (DMSO). The resultant solution contains the recyclable gold electrode and the mp- $\mathrm{TiO}_{2}$-coated TCG substrate (Supplementary Fig. 1); the recycling procedure is shown in Supplementary Movie 1. After rinsing and drying of the selectively dissolved $\mathrm{mp}-\mathrm{TiO}_{2}$-coated TCG substrate, the MALI layer, HTL and gold electrode are re-deposited to yield a recycled PSC.

The effect of the polar aprotic solvent on the removal of the MALI perovskite material was determined via field-emission scanning electron microscopy (FESEM). Figure 2a,b show plane-view images of the mp- $\mathrm{TiO}_{2}$ layer coated on the TCG substrate and the MALI layer deposited on top of the mp- $\mathrm{TiO}_{2}$ layer, respectively. After selective dissolution processing of the MALI-coated substrate using DMF, the MALI layer is easily removed and only the mp- $\mathrm{TiO}_{2}$ layer is observed (Fig. 2c). We determined the efficacy of this recycling process by repeatedly recycling (in this work, we performed a total of 10 cycles) the $\mathrm{mp}-\mathrm{TiO}_{2}$-coated TCG substrate of the PSC. The photocurrent density-voltage $(J-V)$ curve of a 10-times-recycled device is similar to that of a PSC based on a new substrate (Fig. 2d and Supplementary Fig. 2). These results indicate that PSCs can be easily recycled.

Recycling mechanism. The selection of an appropriate solvent is essential for an effective recycling process. To investigate the solvent effect, we immersed PSCs in non-polar and protic/aprotic polar solvents. In the case of the non-polar solvents, only the $\mathrm{Au} / \mathrm{HTL}$ was removed from the Au/HTL/MALI/mp-TiO $/$ /TCG substrate, indicating that non-polar solvents selectively dissolve the spiro-MeOTAD layer (Table 1 and Fig. 3). The perovskite layer decomposed in both types of polar solvents, albeit with differing dissolution behaviours. This layer can dissolve in hydrogen-bonded polar protic solvents, such as ethanol or water. However, the dissolution kinetics is quite sluggish compared with the kinetics governing dissolution in a polar aprotic solvent. When the PSCs were immersed in the polar protic solvents, the perovskite layers became yellow in colour and, after more than 
a

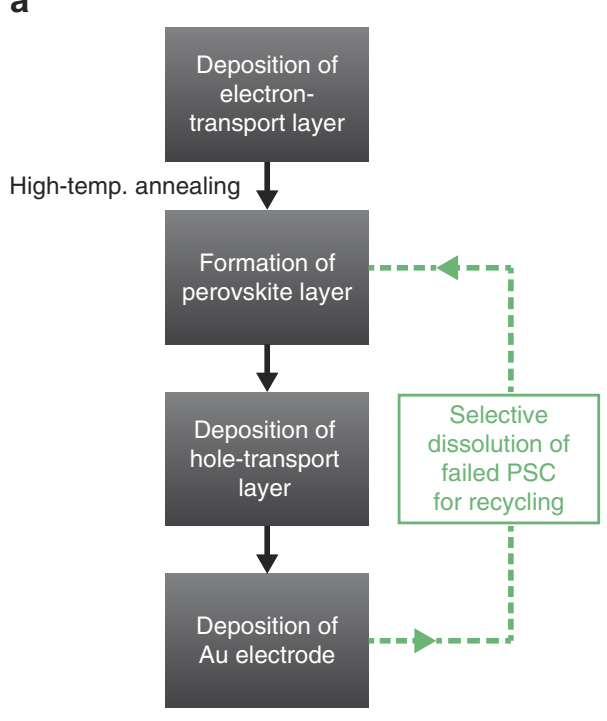

b

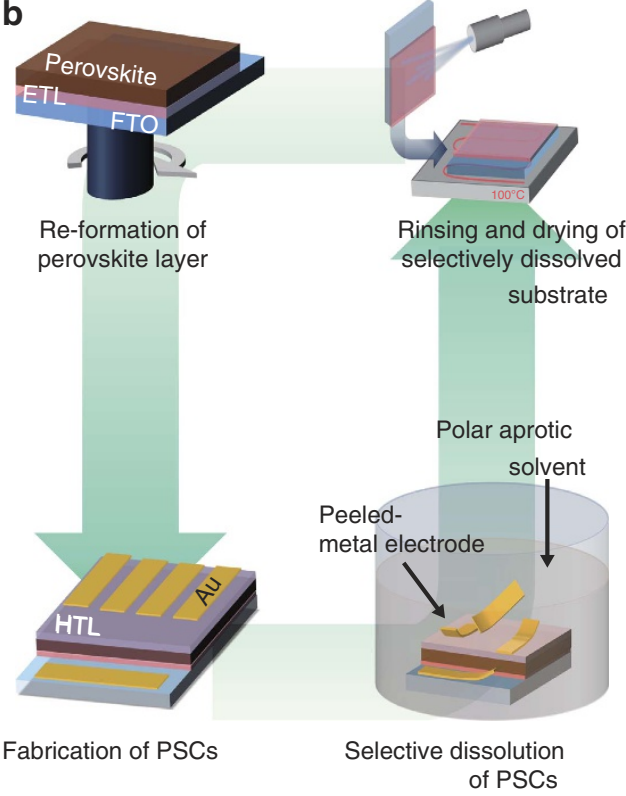

Figure 1 | Recycling process for PSCs. (a) Flow chart of the fabrication and recycling processes for PSCs. (b) Schematic illustration of the detailed process of recycling PSCs via selective dissolution. During soaking in a polar aprotic solvent, the deposited-metal electrode peels away from the device, leaving the clear electron-transport-layer-coated substrate behind, and the hole-transport layer and perovskite layer dissolve.
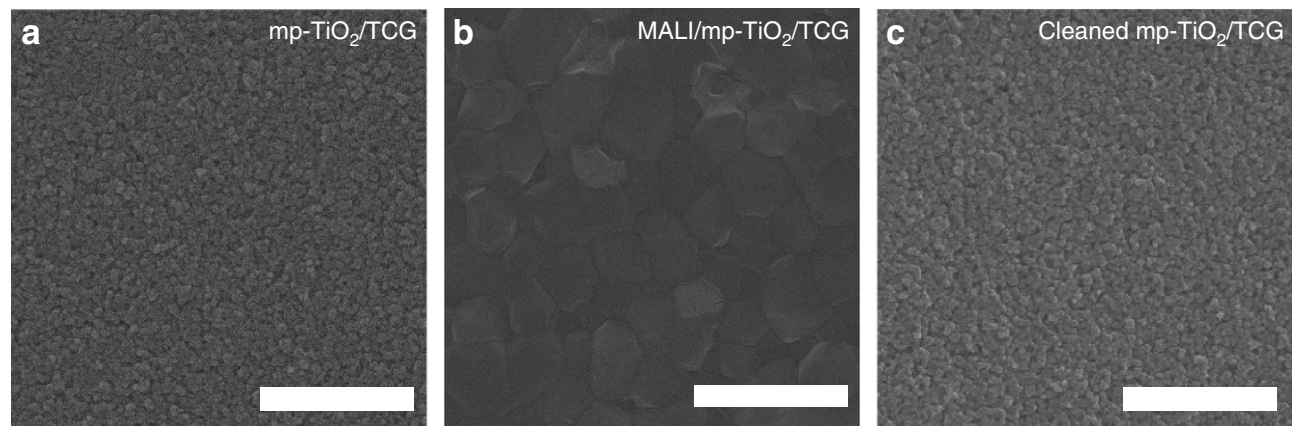

d

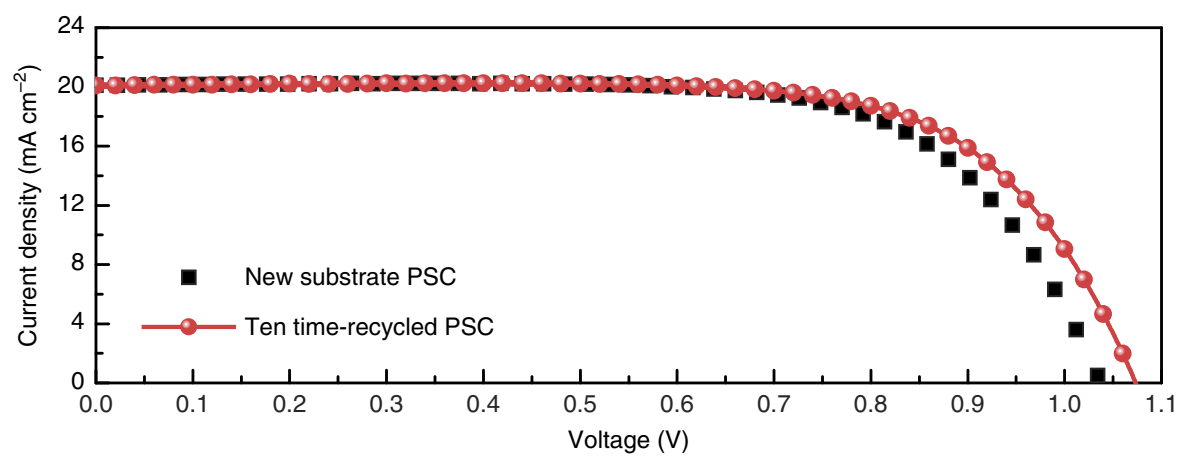

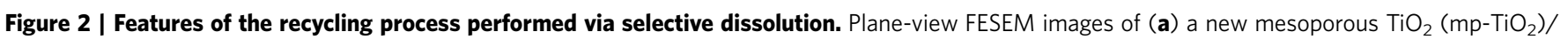
TCG substrate, (b) a $\mathrm{CH}_{3} \mathrm{NH}_{3} \mathrm{Pbl}_{3}$ (MALI)-layer-deposited mp- $\mathrm{TiO}_{2} / \mathrm{TCG}$ substrate and (c) a cleaned mp-TiO $/$ TCG substrate after the selective dissolution process. For the cleaning of the $\mathrm{MALI} / \mathrm{mp}-\mathrm{TiO}_{2} / \mathrm{TCG}$ substrate, DMF was used. Scale bars, $1 \mu \mathrm{m}$. (d) Current density-voltage $(J-V)$ curve of a PSC fabricated on a 10-times-recycled $\mathrm{mp}-\mathrm{TiO}_{2} / \mathrm{TCG}$ substrate compared with that of a PSC fabricated on a new substrate.

$24 \mathrm{~h}$, eventually became transparent (Supplementary Fig. 3). This behaviour is attributable to the constituent organic cations (such as the methylamine group) of the perovskite light absorber, which easily dissolve in hydrogen-bonded solvents (for example, $\mathrm{H}_{2} \mathrm{O}$, ethanol); the low solubility of metal halides (for example, $\mathrm{PbI}_{2}$ and $\left.\mathrm{PbBr}_{2}\right)$ in polar protic solvents is indicative of the relatively slow $\mathrm{S}_{\mathrm{N}} 2$ reaction compared with that in a polar aprotic solvent ${ }^{9,10}$. A polar aprotic solvent can dissolve the perovskite layer completely within a fairly short time after immersion. We tested the dissolution of PSCs in various other solvents, as shown in Supplementary Fig. 4. The results of these attempts were consistent with the results described above. 
To determine whether the bonding between the metal halide and the aprotic solvent plays an important role in the recycling process, ${ }^{13} \mathrm{C}$ nuclear magnetic resonance (NMR) measurements were performed at $500 \mathrm{MHz}$ using DMF, $1 \mathrm{M} \mathrm{PbI}_{2}$ in $\mathrm{DMF}$ and $1 \mathrm{M} \mathrm{CH}_{3} \mathrm{NH}_{3} \mathrm{PbI}_{3}$ in DMF (the full range of the $500 \mathrm{MHz} \mathrm{NMR}$ results is shown in Supplementary Fig. 5a). As Fig. 4a,b show, the main NMR peaks of the $\mathrm{PbI}_{2}-\mathrm{DMF}$ solution (red lines) were

\section{Table 1 | Various solvents used for the selective dissolution of the perovskite layer and their dipole moments.}

\begin{tabular}{lcc} 
Solvent & Chemical formula & Dipole moment (D) \\
\hline Non-polar solvents & & \\
Toluene & $\mathrm{C}_{6} \mathrm{H}_{5}-\mathrm{CH}_{3}$ & 0.375 \\
Diethyl ether & $\mathrm{CH}_{3}-\mathrm{CH}_{2}-\mathrm{O}-\mathrm{CH}_{2}-\mathrm{CH}_{3}$ & 1.15 \\
Dichoromethane & $\mathrm{CH}_{2} \mathrm{Cl}_{2}$ & 1.60 \\
Chlorobenzene & $\mathrm{C}_{6} \mathrm{H}_{5}-\mathrm{Cl}$ & 1.69 \\
& & \\
Polar protic solvents & & 1.58 \\
2-Propanol & $\mathrm{CH}_{3}-\mathrm{CH}(-\mathrm{OH})-\mathrm{CH}_{3}$ & 1.69 \\
Ethanol & $\mathrm{CH}-\mathrm{CH}-\mathrm{OH}$ & 1.70 \\
Methanol & $\mathrm{CH}-\mathrm{OH}$ & 1.85 \\
Water & $\mathrm{H}-\mathrm{O}-\mathrm{H}$ & \\
& & 2.88 \\
Polar aprotic solvents & & 3.82 \\
Acetone & $\mathrm{CH}_{3}-\mathrm{C}(=\mathrm{O})-\mathrm{CH}_{3}$ & 3.92 \\
Dimethylformamide & $\mathrm{H}-\mathrm{C}(=\mathrm{O}) \mathrm{N}\left(\mathrm{CH}_{3}\right)_{2}$ & 3.96 \\
Acetonitrile & $\mathrm{CH}-\mathrm{C} \equiv N$ & 4.27 \\
Dimethyl sulfoxide & $\mathrm{CH}_{3}-\mathrm{S}(=\mathrm{O})-\mathrm{CH}_{3}$ & \\
$\gamma$-Butyrolactone & $/-\mathrm{C}_{2} \mathrm{H}_{4}-\mathrm{O}-\mathrm{C}{ }_{2} \mathrm{H}_{4}-\backslash=\mathrm{O}$ & \\
\hline
\end{tabular}

shifted downwards compared with those of the DMF solution (blue lines). These results are consistent with the formation of metal halide-DMF bonds; $\mathrm{PbI}_{2}$ bonds with the DMF molecule, resulting in the formation of a $\mathrm{PbI}_{2}-\mathrm{DMF}$ structure via the $\mathrm{Pb}-\mathrm{O}$ bond ${ }^{9-11}$. Because of the resonance structure of DMF (Supplementary Fig. 6), the partially negative oxygen atom in DMF can bond with partially positive atoms, such as $\mathrm{Pb}^{2+}$ cations (Fig. 4c). Therefore, aprotic solvents (such as DMF) have the ability to form $\mathrm{PbI}_{2}-\mathrm{DMF}$ compounds, as shown in Fig. $4 \mathrm{~d}$. The chemical shifts of the ${ }^{13} \mathrm{C} \mathrm{sp}^{2}$ and ${ }^{13} \mathrm{C} \mathrm{sp}^{3}$ signals corresponding to the $\mathrm{CH}_{3} \mathrm{NH}_{3} \mathrm{PbI}_{3}-\mathrm{DMF}$ solution (see Fig. $4 \mathrm{a}$,b (black lines)) are similar to those for the $\mathrm{PbI}_{2}-\mathrm{DMF}$ solution. These ${ }^{13} \mathrm{C}-\mathrm{NMR}$ results indicate that the $\mathrm{Pb}^{2}+$ cations in the $\mathrm{CH}_{3} \mathrm{NH}_{3} \mathrm{PbI}_{3}$ perovskite layer readily bond with the partially negative oxygen atoms in aprotic solvents (Fig. 4e). This bonding enables dissociation of the $\mathrm{PbI}_{6}$ octahedral frame that forms the skeleton of the organic-inorganic perovskite material, thereby resulting in high solubility of the perovskite material in polar aprotic solvents.

As shown in Supplementary Movie 1, the used gold electrode can be easily collected during the recycling process. Supplementary Table 1 shows that the collected gold electrodes contained $0.41 \%$ lead impurities. The refining of metal collected from electronic and solution wastes is one of the most universal processes for the recycling of metal in industry ${ }^{12}$. Refined gold originating from industrial disposal represents $4 \%$ of the entire gold market in the industrial field ${ }^{13}$. Thus, the gold gathered during the recycling process can be easily refined because of its low impurity concentration. Another important problem to be addressed is the removal of lead pollutants from the residual polar
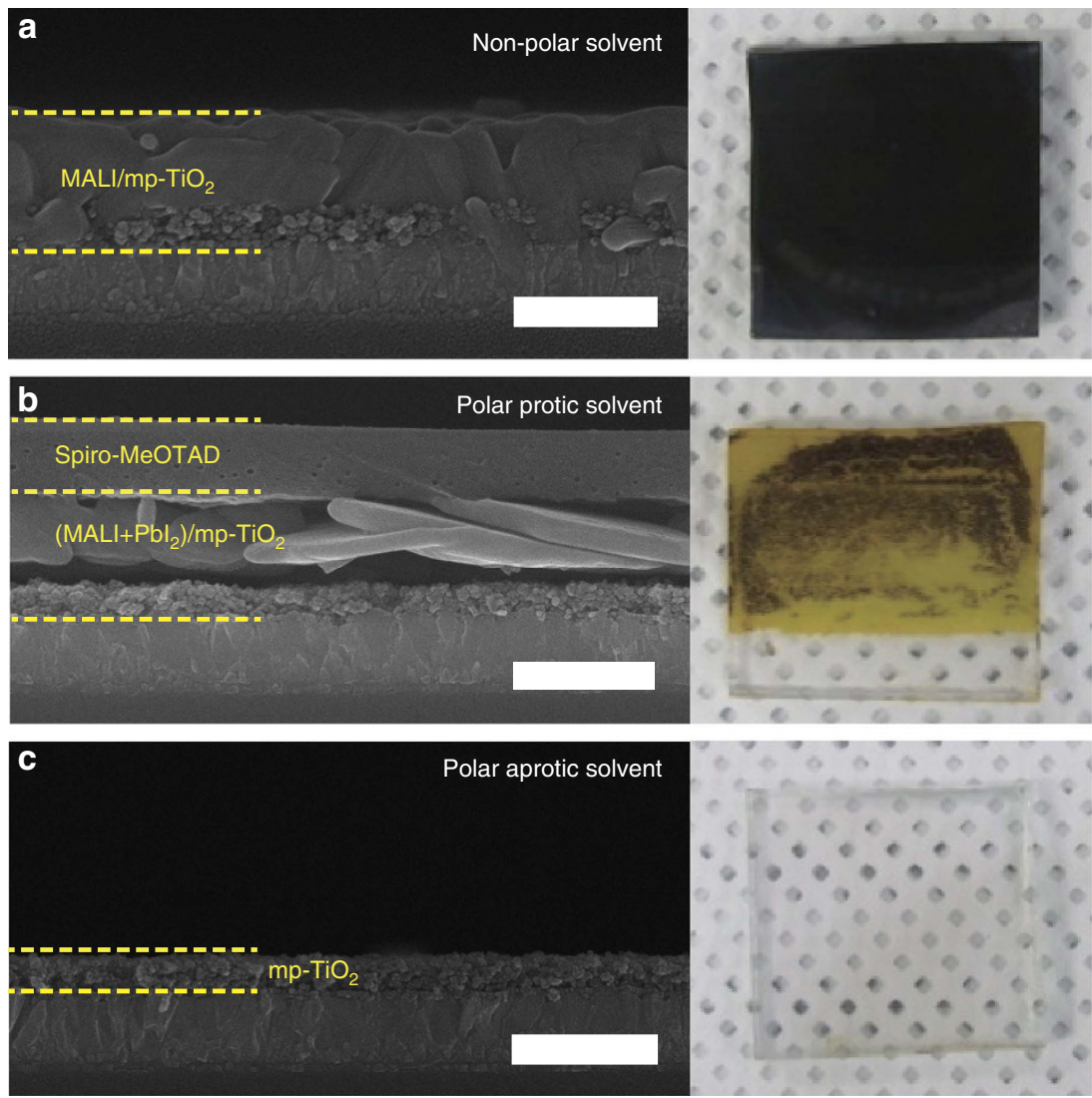

Figure 3 | Features of PCSs dissolved in three different types of solvents. Cross-sectional FESEM and photographic images of dissolved PCSs obtained after $30 \mathrm{~s}$ of immersion of spiro-MeOTAD/MALI/mp-TiO $/ 2 / \mathrm{TCG}$ in (a) non-polar, (b) polar protic and (c) polar aprotic solvents. Diethyl ether, water and DMF, respectively, were used as the representative solvents. Scale bars, $700 \mathrm{~nm}$. 
a

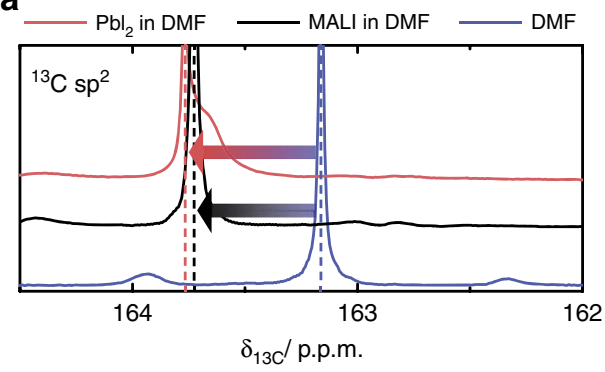

b

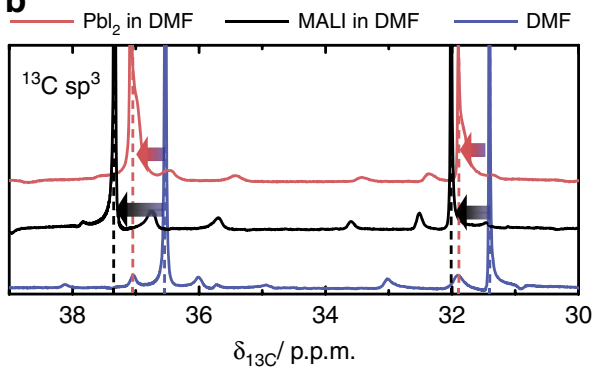

C

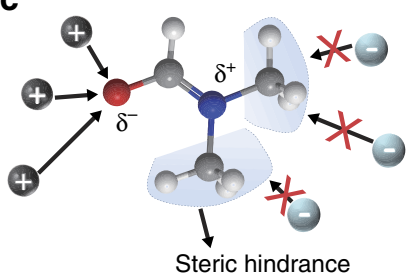

d

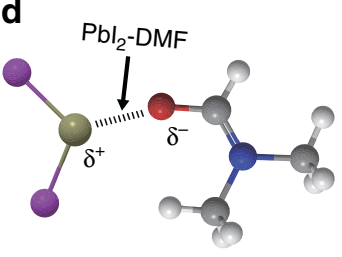

e

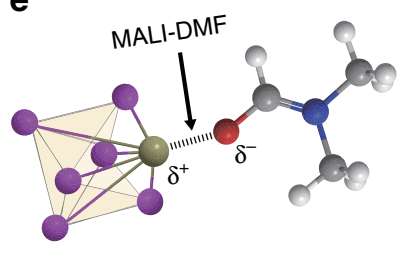

Figure 4 | Dissolution mechanism of MALI in a polar aprotic solvent. (a) ${ }^{13} \mathrm{C} \mathrm{sp}^{2}$ and (b) ${ }^{13} \mathrm{C} \mathrm{sp}^{3} \mathrm{chemical} \mathrm{shifts} \mathrm{of} \mathrm{Pbl}{ }_{2}-\mathrm{DMF}$ and $\mathrm{MALI}-\mathrm{DMF}$ away from the corresponding signals for a pure DMF solution. (c) Scheme of the resonance structure of DMF, with a partially positive and negative polarity. Chemical bonding structures of the (d) $\mathrm{Pbl}_{2}$ and (e) Pbl 6 frames of MALI with the partially negative oxygen of DMF. (Red spheres: oxygen, blue spheres: nitrogen, grey spheres: carbon, white spheres: hydrogen, yellow spheres: lead, violet spheres: iodine.)

aprotic solvent after the recycling process because of the attendant economic and environmental issues. Several methods of removing lead from lead-containing solution wastes have been investigated, such as electrodialysis ${ }^{14}$, solvent extraction ${ }^{15}$, ion exchange $^{16}$ and biosorption ${ }^{17}$. In particular, hydroxyapatite $\left(\mathrm{Ca}_{10}\left(\mathrm{PO}_{4}\right)_{6}(\mathrm{OH})_{2}\right.$, also called HAP), a biocompatible material present in human bone and teeth, shows a remarkable efficiency for the absorption of $\mathrm{Pb}^{2+}$ ions through ion exchange between $\mathrm{Ca}^{2+}$ and $\mathrm{Pb}^{2+}$ (refs 18,19). We also demonstrated a lead-removal treatment for residual-lead-containing solution waste via a two-step process combining solvent extraction and ion exchange (Supplementary Fig. 7). In the first step, the lead concentration in a waste solution of 0.05 M MALI in DMF, which was initially 2,017,791.3 p.p.b. (equivalent to $\mu \mathrm{g} \mathrm{kg}^{-1}$ ), was decreased to 28,507.8 p.p.b. during the solvent extraction process. Then, after an ion exchange process with $50 \mathrm{mg}$ HAP, the concentration of residual lead was decreased to 67.4 p.p.b., corresponding to a $99.99 \%$ reduction in lead concentration compared with that of the initial solution. Thus, these results show that the proposed two-step lead-removal process is effective in separating lead compounds from residual-lead-containing solution waste.

Surface analysis of a dissolved $\mathrm{mp}$ - $\mathrm{TiO}_{2}$-coated FTO substrate. The optical transmittance spectra of an as-prepared $\mathrm{mp}-\mathrm{TiO}_{2}$ coated FTO substrate, a MALI/mp- $\mathrm{TiO}_{2} / \mathrm{FTO}$ substrate and a cleaned $\mathrm{mp}-\mathrm{TiO}_{2} / \mathrm{FTO}$ substrate are shown in Fig. 5a. The transmittance of the MALI/mp- $\mathrm{TiO}_{2} / \mathrm{FTO}$ substrate is significantly lower than that of the as-prepared $\mathrm{mp}-\mathrm{TiO}_{2} / \mathrm{FTO}$ substrate, owing to the large absorption coefficient of the MALI layer. After the perovskite layer is removed, the transmittance is restored to that of the as-prepared substrate, indicating that perovskite-layer removal and the dissolution process do not affect the optical properties of the substrate. Figure $5 \mathrm{~b}$ shows the X-ray diffraction patterns of the films ${ }^{20}$. The peaks in the pattern of the DMF-cleaned $\mathrm{mp}-\mathrm{TiO}_{2} / \mathrm{FTO}$ substrate correspond only to anatase $\mathrm{TiO}_{2}$ and FTO, indicating that the perovskite layer was removed by the DMF solvent. The surface state of the cleaned substrate was determined from atomic depth profiles obtained via secondary ion mass spectrometry (SIMS) for each film. As Fig. 5d shows, $\mathrm{Pb}$ and I were present in the $\mathrm{MALI} / \mathrm{mp}-\mathrm{TiO}_{2} / \mathrm{FTO}$ substrate. The X-ray diffraction pattern of the sample (Fig. 5b) indicates that these elements are components of the MALI perovskite material. These were detected even after the perovskite layer was removed, indicating that residual $\mathrm{Pb}^{2+}$ and $\mathrm{I}^{-}$ions (not detected via $\mathrm{X}$-ray diffraction) were present on the surface of the $\mathrm{mp}-\mathrm{TiO}_{2}$ layer (Fig. 5e). Supplementary Fig. 8 shows the X-ray photoemission spectra of the films. Consistent with the X-ray diffraction and SIMS data, the presence of $\mathrm{Pb}$ and I peaks in the signal from the pre-dissolution sample indicates that a perovskite layer formed on the $\mathrm{MALI} / \mathrm{mp}-\mathrm{TiO}_{2} / \mathrm{FTO}$ substrate.

The X-ray photoemission spectra of the cleaned $\mathrm{mp}-\mathrm{TiO}_{2} / \mathrm{FTO}$ substrate also contain $\mathrm{Pb}$ and I peaks. Figure 5f,h and Fig. 5g,i show the X-ray photoemission spectra of the MALI/ $\mathrm{mp}-\mathrm{TiO}_{2} / \mathrm{FTO}$ substrate and the cleaned $\mathrm{mp}-\mathrm{TiO}_{2} / \mathrm{FTO}$ (inset) substrate, respectively. The binding energies of $\mathrm{Pb} 4 f(142.8$ and $137.9 \mathrm{eV})$ and $\mathrm{I} 3 d(630.6$ and $619.1 \mathrm{eV})$, shown in Fig. 5f,h, respectively, indicate that the $\mathrm{Pb}$ and $\mathrm{I}$ ions were incorporated into the MALI perovskite structure ${ }^{21,22}$. The peaks in Fig. $5 \mathrm{~g}, \mathrm{i}$ corresponding to the binding energies of $\mathrm{Pb}$ and I ions remaining on the surface of the cleaned $\mathrm{mp}-\mathrm{TiO}_{2} / \mathrm{FTO}$ substrate appear in positions that are typical of $\mathrm{PbI}_{2}$ (refs 23,24).

We also investigated the surface states of cleaned $\mathrm{mp}-\mathrm{TiO}_{2} / \mathrm{FTO}$ substrates that had been selectively dissolved with various cleaning times (from 1 to $10 \mathrm{~min}$ ) and numbers of recycling cycles (from one to five cycles with $30 \mathrm{~s}$ of rinsing between each cycle) for complete removal of residual $\mathrm{PbI}_{2}$ and confirmation of the accumulation of residual $\mathrm{PbI}_{2}$, respectively. Supplementary Fig. 9a,b show that the intensities of the $\mathrm{Pb} 4 f$ peak for cleaned $\mathrm{mp}-\mathrm{TiO}_{2} / \mathrm{FTO}$ substrates treated with various cleaning times (from 1 to $10 \mathrm{~min}$ ) and in multiple cleaning cycles (from one to four cycles) were of similar intensity regardless of the cleaning conditions. Furthermore, the $\mathrm{Pb} 4 f$ peak of the five-times-recycled $\mathrm{mp}-\mathrm{TiO}_{2} / \mathrm{FTO}$ also showed a similar intensity to that of the once-recycled substrate (Supplementary Fig. 9c). It appears impossible to remove the residual $\mathrm{PbI}_{2}$ completely, but the amount of residual $\mathrm{PbI}_{2}$ on the $\mathrm{TiO}_{2}$ surface was negligible compared with that in the original MALI layer, and no accumulation of residual $\mathrm{PbI}_{2}$ occurred under repeated recycling. 
a

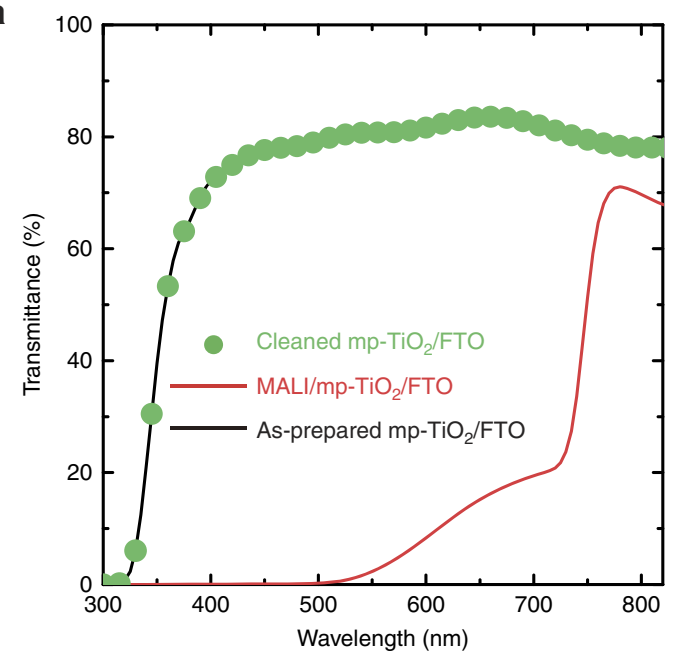

c

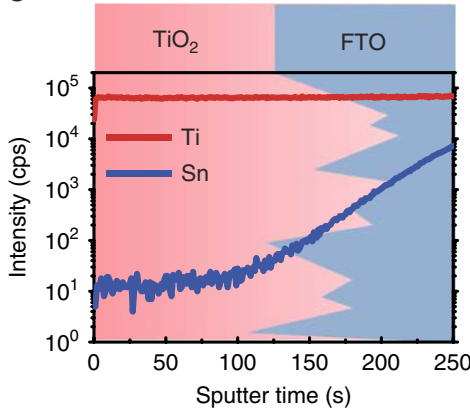

d

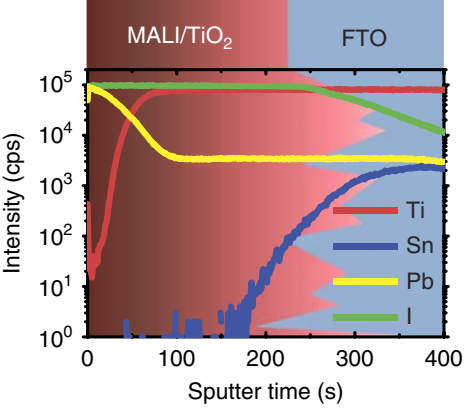

b

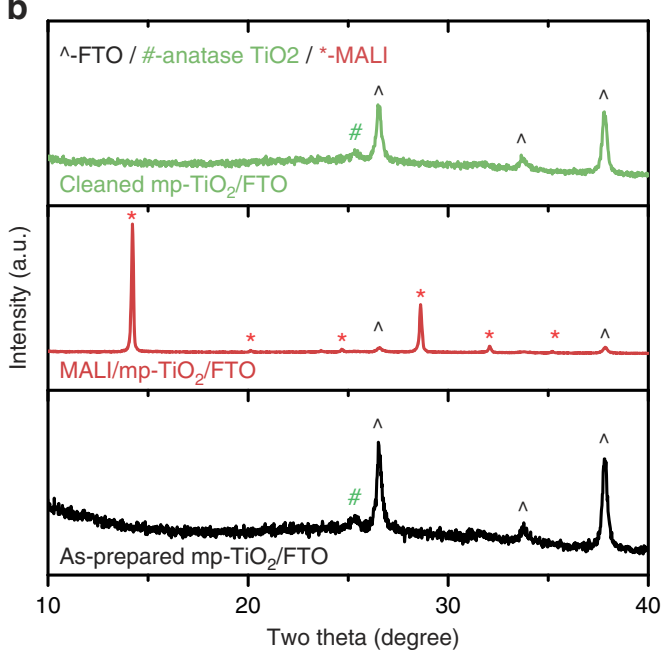

e

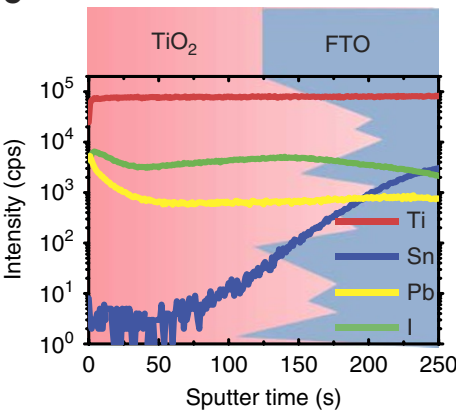

f

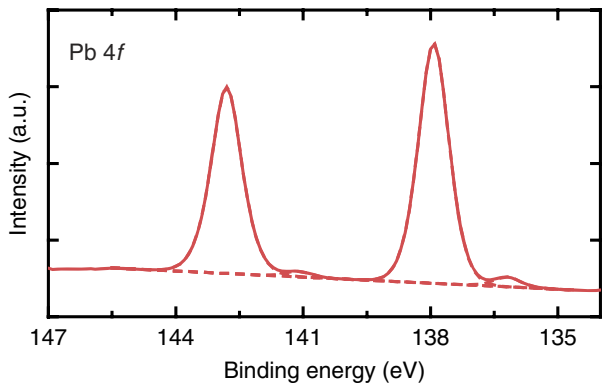

g

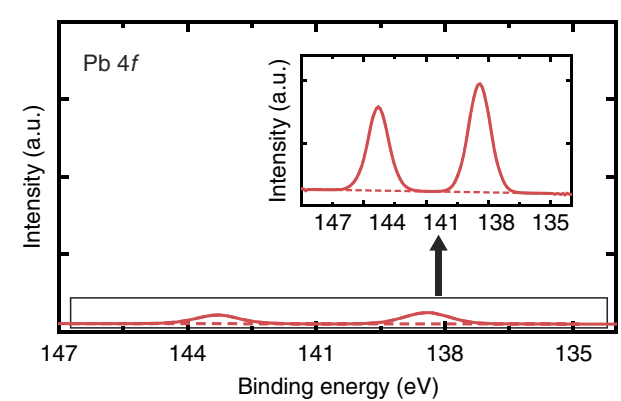

h

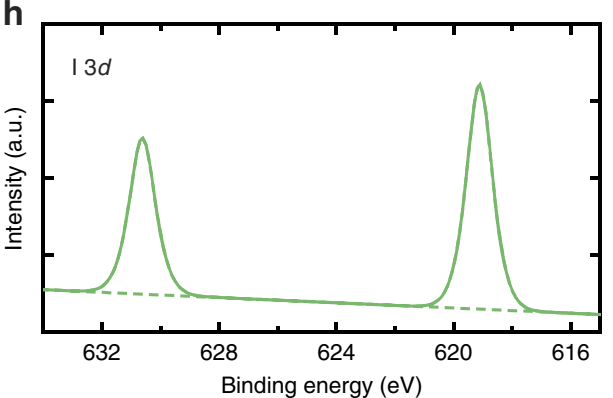

i

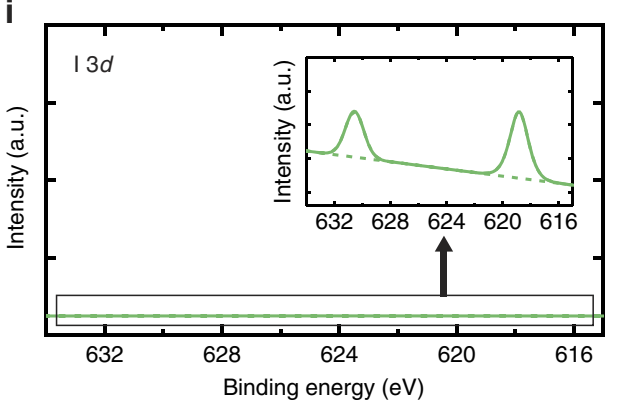

Figure 5 | Optical and surface analysis before/after selective dissolution of the substrate. After the recycling process using a polar aprotic solvent, (a) the optical transmittance is preserved and (b) the X-ray diffraction patterns of the cleaned $\mathrm{mp}-\mathrm{TiO}_{2} / \mathrm{FTO}$ substrate exhibit peaks corresponding to anatase $\mathrm{TiO}_{2}$ and $\mathrm{FTO}$ without MALI or $\mathrm{Pbl}_{2}$ ( ${ }^{\wedge}$ with black: $\mathrm{FTO}$, \# with green: anatase $\mathrm{TiO}_{2},{ }^{*}$ with red: MALI). Results of secondary ion mass spectroscopy performed on (c) as-prepared mp- $\mathrm{TiO}_{2} / \mathrm{FTO}$, (d) $\mathrm{MALI} / \mathrm{mp}-\mathrm{TiO}_{2} / \mathrm{FTO}$ and (e) cleaned mp- $\mathrm{TiO}_{2} / \mathrm{FTO}$. The background schematics of the spectra represent the device structure; thus, the initial values of the spectra at $0 \mathrm{~s}$ of sputtering time represent each ion concentration at the surface of each substrate. The results for the cleaned $\mathrm{mp}-\mathrm{TiO}_{2} / \mathrm{FTO}$ substrate reveal the presence of residual $\mathrm{Pb}^{2+}$ and $\mathrm{I}^{-}$ions on the cleaned substrate. X-ray photoemission spectra of $(\mathbf{f}, \mathbf{g}) \mathrm{Pb} 4 f$ and $(\mathbf{h}, \mathbf{i}) \mathrm{I} 3 d$ on the substrate before and after selective dissolution, respectively. The binding energies of $\mathrm{Pb} 4 f$ and I $3 d$ correspond to $\mathrm{Pb}$ and I in the perovskite layer and in the form of residual $\mathrm{Pbl}_{2}$ on the $\mathrm{mp}-\mathrm{TiO}_{2} / \mathrm{FTO}$ and cleaned $\mathrm{mp}-\mathrm{TiO}_{2} / \mathrm{FTO}$ substrates, respectively. 
Other groups have investigated the effect of non-stoichiometric $\mathrm{MAI} / \mathrm{PbI}_{2}$ molar ratios (of $\mathrm{PbI}_{2}$ and $\mathrm{CH}_{3} \mathrm{NH}_{3} \mathrm{I}$ (MAI)) on perovskite crystal growth or crystallinity, leading to improved PV properties; molar ratios ranging from 0.83 to 1.2 were considered in those studies ${ }^{25,26}$. In addition, Cao et al. have reported that residual $\mathrm{PbI}_{2}$, which forms between the perovskite and the $\mathrm{TiO}_{2}$, acts as a charge-recombination-hindering layer ${ }^{27}$. No such phenomenon was observed in the present study, in which the performance of the recycled PSCs remained stable, even in the presence of $\mathrm{PbI}_{2}$. Therefore, a polar aprotic solvent is capable of dissolving MALI perovskite materials within a rather short amount of time, although the $\mathrm{PbI}_{2}$ on the $\mathrm{TiO}_{2}$ surface is only partially dissolved. The residual $\mathrm{PbI}_{2}$ layer does not affect the PV properties of the regenerated PSC, thus enabling the recycling of these cells.
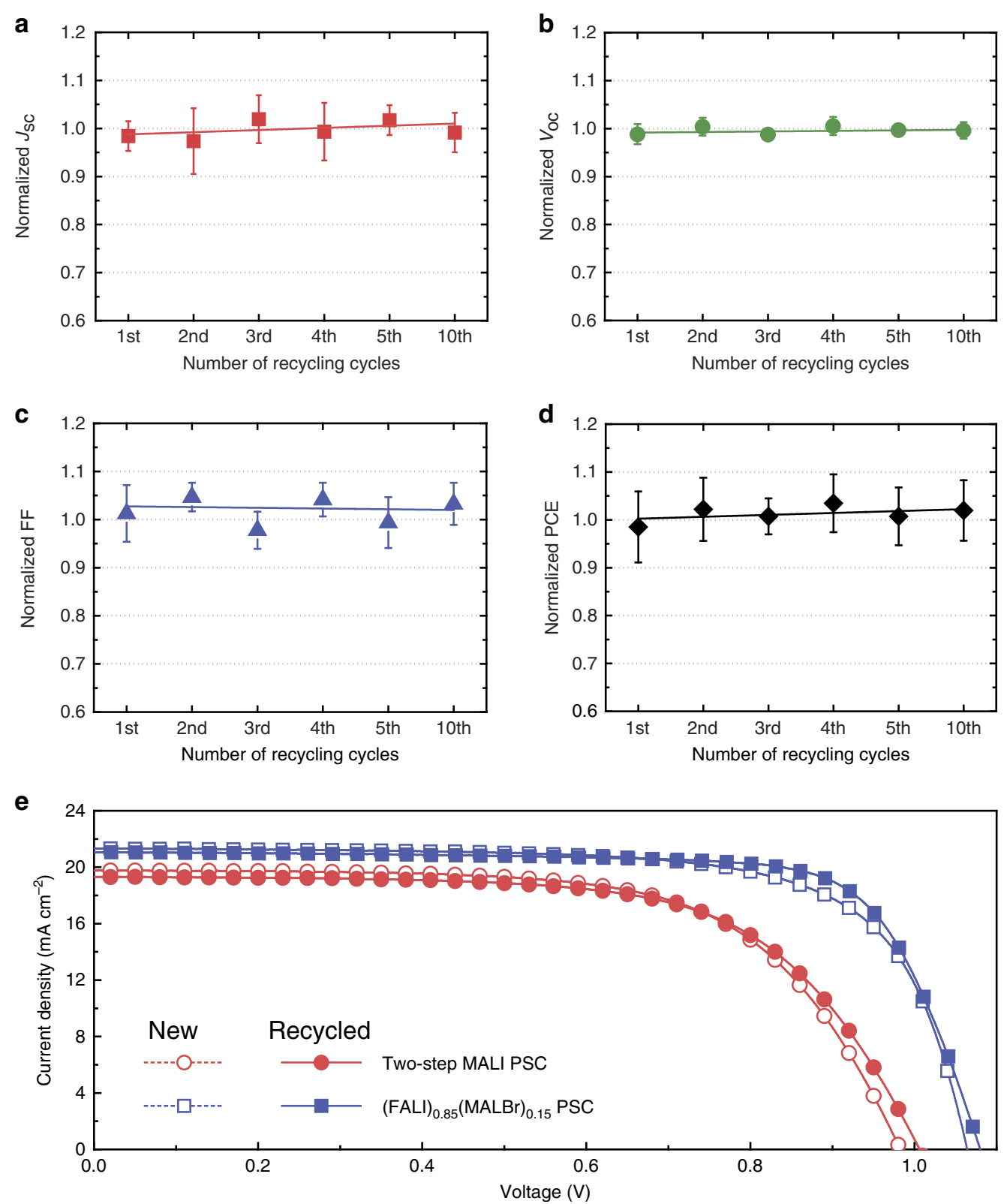

Figure 6 | Photovoltaic performance characteristics of recycled PSCs. Normalized trends in the (a) short-circuit current density, (b) open-circuit voltage, (c) fill factor and (d) efficiency of MALI-based PSCs fabricated on 1st-, 2nd-, 3rd-, 4th-, 5th- and 10th-time recycled substrates compared with those of the MALI-PSC fabricated on the newly prepared substrate. (e) J-V curves for two-step processed MALI-based PSCs (red spheres) and $(\mathrm{FALI})_{0.85}(\mathrm{MALBr})_{0.15}$-based PSCs (blue squares) on new (dotted lines and empty symbols) and once-recycled (solid lines and filled symbols) $\mathrm{mp}-\mathrm{TiO}_{2} / \mathrm{TCG}$ substrates. The error bars in a-d indicate the s.d.'s calculated from five samples.

\section{Discussion}

The nearly constant PV performance observed during the

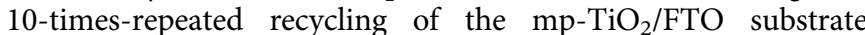
(see Fig. 6) demonstrates the recyclability of PSCs using the proposed method. Furthermore, a recycled MALI-PSC, fabricated using a cleaned $\mathrm{mp}-\mathrm{TiO}_{2} / \mathrm{FTO}$ substrate recovered from a degraded MALI-PSC through selective dissolution, exhibited a performance comparable to that of the MALI-PSC based Four individual cells were measured for each type of device to investigate the influence of the recycling process on long-term stability. The recycled MALI-PSC device showed stability comparable to that of the fresh MALI-PSC device (Supplementary Fig. 11 and Supplementary Table 2). To confirm the feasibility of the recycling process for various fabrication 
processes, such as a two-step process, and for different compositions, such as formamidinium- or bromide-containing perovskite, we fabricated two-step MALI- and (FALI) 0.85 $(\mathrm{MALBr})_{0.15}$-based PSCs using our selective dissolution recycling process. The results presented in Fig. 6e show that the selective dissolution process is also compatible with other perovskite fabrication processes and with PSCs based on different compositions. These results clearly demonstrate that our recycling process does not influence the PV performance and that it is generally applicable to PSCs of any kind prepared with different perovskite deposition processes and compositions. We also found that the recycling process is applicable to planar-structured and flexible PSCs (Supplementary Fig. 12).

These results may change the current paradigm in the field of solar cells and their application. Although the stability of PSCs remains an important issue, the long-term stability of PSCs is not as essential as it is in the case of commercialized solar cells. If PSCs can be easily refurbished, then these cells can be used as batteries that could become available in consumer products. The combination of high efficiency, recyclability and plastic-based flexibility in PSC technology will shift the paradigm of utilization of perovskite-based PV devices.

\begin{abstract}
Methods
Materials. All materials, except for 1-butanol (Tokyo Chemical Industry), were purchased from Sigma-Aldrich. All materials were used as received. Methylammonium iodide $\left(\mathrm{CH}_{3} \mathrm{NH}_{3} \mathrm{I}, \mathrm{MAI}\right)$ was synthesized using a previously reported method $^{28}$. A solution of 57 wt.\% hydriodic acid in water and a solution of 33 wt.\% methylamine $\left(\mathrm{CH}_{3} \mathrm{NH}_{2}\right)$ in absolute ethanol were stirred into $100 \mathrm{ml}$ of ethanol at room temperature. The precipitate, methylamine iodide, was obtained using a rotary evaporator. Formamidinium iodide $\left(\mathrm{HC}\left(\mathrm{NH}_{2}\right)_{2} \mathrm{I}, \mathrm{FAI}\right)$ was prepared using a previously reported method ${ }^{29}$, in which $25.2 \mathrm{~g}$ and $48 \mathrm{ml}$ of formamidine acetate and hydriodic acid, respectively, were mixed into $250 \mathrm{ml}$ of methanol and reacted at room temperature for $2 \mathrm{~h}$. The resulting precipitate was collected using a rotary evaporator. The synthesized MAI and FAI were washed with diethyl ether and then recrystallized from ethanol and dried in a vacuum oven overnight.
\end{abstract}

Recycling process. The selective dissolution process for recycling $\mathrm{mp}-\mathrm{TiO}_{2} / \mathrm{TCG}$ substrates that have been used in PSCs consisted of several simple steps. In the first step, the trihalide perovskite layer and spiro-MeOTAD were removed by immersing the PSCs in a polar aprotic solvent, such as DMF, GBL or DMSO. The PSCs were then shaken for $30 \mathrm{~s}$ in solution. The cleaned $\mathrm{mp}-\mathrm{TiO}_{2} / \mathrm{TCG}$ substrates were rinsed with deionized water and then dried on a hot plate. For optimal performance, the cleaned substrates were annealed at $500^{\circ} \mathrm{C}$ for $1 \mathrm{~h}$. The gold $(\mathrm{Au})$ material in the PSCs does not react with polar aprotic solvents, and, therefore, the gold that remained in the solutions after cleaning could be collected.

The removal of lead from a polar aprotic solvent used for the recycling process was performed via a two-step process combining solvent extraction with ion exchange. The prepared solution of $0.05 \mathrm{M}$ MALI in DMF was poured into ether, a non-polar solvent. The precipitated lead compound was separated via centrifugation at 8,000 r.p.m. for $10 \mathrm{~min}$. A laboratory-prepared HAP powder (between 10 and $50 \mathrm{mg}$ ) was added to the remaining solution to remove residual $\mathrm{Pb}^{2+}$ ions via ion exchange (from $\mathrm{Ca}^{2+}$ to $\mathrm{Pb}^{2+}$ ). After the addition of the HAP powder, the solution was stirred at 200 r.p.m. for $3 \mathrm{~h}$. After sufficient stirring, the $\mathrm{Pb}^{2+}$-ion-adsorbed HAP powder was separated using a centrifuge at 8,000 r.p.m. for $10 \mathrm{~min}$. The solution remaining after the completion of each step was analysed via inductively coupled plasma-mass spectrometry (Perkin-Elmer SCIEX,

NexION). All solutions were analysed three times, and the results were averaged.

Synthesis of hydroxyapatite. HAP with a high surface area was synthesized using a hydrothermal method based on a previous report by Jiang et al. ${ }^{30}$. In a typical synthesis procedure, $2 \mathrm{mmol}$ of $\mathrm{CaCl}_{2} \cdot 2 \mathrm{H}_{2} \mathrm{O}$ (Sigma-Aldrich, $\geq 99 \%$ ) and $1 \mathrm{~g}$ of poly-L-aspartic acid sodium salt (Sigma-Aldrich, mol. wt. 5,000-15,000) was dissolved in $20 \mathrm{ml}$ of deionized water under $30 \mathrm{~min}$ of stirring (solution 1). Then, $1.2 \mathrm{mmol}$ of $\left(\mathrm{NH}_{4}\right)_{2} \mathrm{HPO}_{4}$ (Sigma-Aldrich, $\geq 98 \%$ ) was dissolved in $15 \mathrm{ml}$ of deionized water under vigorous stirring for $30 \mathrm{~min}$ (solution 2). After stirring, solution 2 was poured into solution 1 . The mixed solution was sealed in a $50-\mathrm{ml}$ Teflon liner, placed in a stainless steel autoclave and maintained at $200{ }^{\circ} \mathrm{C}$ for $12 \mathrm{~h}$. The precipitated HAP was washed with distilled water and ethanol. After washing, the obtained HAP powder was dried in a freeze dryer for $12 \mathrm{~h}$.

Device fabrication. FTO-coated glass substrates (Pilkington TEC15) were cleaned for $15 \mathrm{~min}$ with acetone, ethanol and DI water in an ultrasonic bath. A compact hole-blocking layer of $\mathrm{TiO}_{2}$ was spin-coated (at 3,000 r.p.m. for $20 \mathrm{~s}$ ) on the substrate, using $0.15 \mathrm{M}$ titanium diisopropoxide bis(acetylacetonate) (75 wt.\% in isopropanol) in anhydrous 1-butanol. This layer was then baked at $130{ }^{\circ} \mathrm{C}$ for 5 min. An $\sim 200$-nm-thick layer of porous $\mathrm{mp}-\mathrm{TiO}_{2}$ was prepared on top of the $\mathrm{TiO}_{2}$ layer using a diluted $\mathrm{TiO}_{2}$ paste (EtOH:Dyesol $18 \mathrm{NRT} \mathrm{TiO}_{2}$ paste in a ratio of 4.5:1) and calcining at $500{ }^{\circ} \mathrm{C}$ for $1 \mathrm{~h}$. The resulting $\mathrm{mp}-\mathrm{TiO}_{2} / \mathrm{FTO}$ substrate was immersed for $15 \mathrm{~min}$ in a $0.04 \mathrm{M} \mathrm{TiCl}_{4}$ solution at $70^{\circ} \mathrm{C}$, rinsed with DI water and then annealed at $500^{\circ} \mathrm{C}$ for $30 \mathrm{~min}$.

The prepared $\mathrm{CH}_{3} \mathrm{NH}_{3} \mathrm{PbI}_{3}$ solution (46 wt. $\% \mathrm{CH}_{3} \mathrm{NH}_{3} \mathrm{I}$ and $\mathrm{PbI}_{2}$, at an equal molar ratio, in a mixture of GBL and DMSO $(7: 3 v / v))$ was spin-coated at 1,000 and 5,000 r.p.m. for 10 and 30 s, respectively. During the 5,000-r.p.m. step, $1 \mathrm{ml}$ of a toluene solution was dropped on the spinning $\mathrm{CH}_{3} \mathrm{NH}_{3} \mathrm{PbI}_{3}$ solution. The spin-coated substrate was then dried at $130^{\circ} \mathrm{C}$ for $20 \mathrm{~min}$ (ref. 31). Subsequently, $30 \mu \mathrm{l}$ of a HTL solution (72 mg of spiro-MeOTAD, $28.8 \mu \mathrm{l}$ of 4-tert-butylpyridine and $17.6 \mu \mathrm{l}$ of Li-TFSI solution ( $720 \mathrm{mg}$ of Li-TFSI in acetonitrile) in $1 \mathrm{ml}$ of chlorobenzene) was formed via spin-coating at 4,000 r.p.m. for 30 s. The $\mathrm{Au}$ electrodes were deposited on the PSCs via thermal evaporation. The substrate size and the active device area were $2 \times 2$ and $0.14 \mathrm{~cm}^{2}$, respectively.

Device characterization. The surface morphology and cross-sectional structure were examined via FESEM (JSM-7600F, JEOL). ${ }^{13} \mathrm{C}$-NMR measurements were performed using a $500-\mathrm{MHz}$ NMR spectrometer (Avance-500, Bruker). In addition, the transmittance spectra of the substrate and the perovskite-coated substrate were collected via UV-vis/NIR spectrometry (Cary 5000, Agilent Technologies). The crystalline structure was determined using an X-ray diffractometer (New D8 Advanced, Bruker). Furthermore, compositional depth profiles of the pristine, perovskite-coated and cleaned substrates were obtained via time-of-flight SIMS (ION-TOF). X-ray photoelectron spectroscopy (X-ray photoemission spectra, Sigma Probe, ThermoVG) was used to determine the chemical states of $\mathrm{Pb}$ and $\mathrm{I}$ on the surfaces of the substrates. The corresponding spectra were acquired using monochromatic $\mathrm{A} 1-\mathrm{K} \alpha$ radiation $(100 \mathrm{~W})$ and were calibrated with respect to the C 1-s level (at $284.5 \mathrm{eV}$ ). Moreover, the PV properties were measured using a solar simulator (Newport Oriel Solar 3A Class AAA, 64023A) equipped with a 450-W xenon lamp (Newport 6279NS) and a potentiostat (CHI 600D, CH Instruments). The light intensity was adjusted using a standard $\mathrm{Si}$ solar cell (Oriel, VLSI standards; 1 sun is equivalent to $100 \mathrm{~mA} \mathrm{~cm}^{-2}$ ).

Data availability. The authors declare that the data supporting the findings of this study are available within the article and its Supplementary Information files.

\section{References}

1. Kim, H.-S. et al. Lead iodide perovskite sensitized all-solid-state submicron thin film mesoscopic solar cell with efficiency exceeding 9\%. Sci. Rep. 2, 591 (2012).

2. Burschka, J. et al. Sequential deposition as a route to high-performance perovskite-sensitized solar cells. Nature 499, 316-319 (2013).

3. Zhou, H. et al. Interface engineering of highly efficient perovskite solar cells. Science 345, 542-546 (2014).

4. NREL, Best Research-Cell Efficiencies http://www.nrel.gov/ncpv/images/ efficiency_chart.jpg (2015).

5. Metz, A. et al.International Technology Roadmap for Photovoltaic (ITRPV.net) Results 2014 http://www.itrpv.net/Reports/Downloads/2015/ (2015).

6. Savage, L. Perovskite photovoltaics: hitting their stride. Opt. Photon. News $\mathbf{2 5}$, 26-33 (2014).

7. U.S. Department of Energy. SunShot Vision Study. Report No. DOE/GO102012-3037. http://www.osa-opn.org/opn/media/Images/PDF/2014/1114/2633_Perovskite-Nov.pdf?ext=.pdf (Department of Energy, 2012).

8. Gong, J. et al. Perovskite photovoltaics: life-cycle assessment of energy and environmental impacts. Energy Environ. Sci. 8, 1953-1968 (2015).

9. Miller, J. et al. Dipolar aprotic solvents in bimoleculer aromatic nucleophilic substitution reactions. J. Am. Chem. Soc. 83, 117-123 (1961).

10. Parker, A. J. The effects of solvation on the properties of anions in dipolar aprotic solvents. Q. Rev. Chem. Soc. 16, 163-187 (1962).

11. Wakamiya, A. et al. Reproducible fabrication of efficient perovskite-based solar cells: $\mathrm{x}$-ray crystallographic studies on the formation of $\mathrm{CH}_{3} \mathrm{NH}_{3} \mathrm{PbI}_{3}$ layers. Chem. Lett. 43, 711-713 (2014).

12. Cui, J. et al. Metallurgical recovery of metals from electronic waste: a review. J. Hazard. Mater. 158, 228-256 (2008).

13. Hagelüken, C. et al. Recycling of gold from electronics: cost-effective use through 'Design for Recycling. Gold Bull. 43, 209-220 (2010).

14. Mohammadi, T. et al. Effect of operating parameters on $\mathrm{Pb}^{2+}$ separation from wastewater using electrodialysis. Desalination 167, 379-385 (2004).

15. Shah, D. B. et al. Lead removal from foundry waste by solvent extraction. J. Air Waste Manage. Assoc. 45, 150-155 (1995).

16. Ahmed, S. et al. The removal of cadmium and lead from aqueous solution by ion exchange with Na-Y zeolite. Sep. Purif. Technol. 13, 57-64 (1998).

17. Axtell, N. R. et al. Lead and nickel removal using microspora and lemna minor. Bioresour. Technol. 89, 41-48 (2003). 
18. Cui, L. et al. Mechanism of $\mathrm{Pb}(\mathrm{II})$ and methylene blue adsorption onto magnetic carbonate hydroxyapatite/graphene oxide. RSC Adv. 5, 9759-9770 (2015).

19. Lei, Y. et al. Bioinspired fabrication and lead adsorption property of nanohydroxyapatite/chitosan porous materials. RSC Adv. 5, 98783-98795 (2015).

20. Kutes, Y. et al. Direct observation of ferroelectric domains in solutionprocessed $\mathrm{CH}_{3} \mathrm{NH}_{3} \mathrm{PbI}_{3}$ perovskite thin films. J. Phys. Chem. Lett. 5, 3335-3339 (2014).

21. Lindblad, R. et al. Electronic structure of $\mathrm{TiO}_{2} / \mathrm{CH}_{3} \mathrm{NH}_{3} \mathrm{PbI}_{3}$ perovskite solar cell interfaces. J. Phys. Chem. Lett. 5, 648-653 (2014).

22. Conings, B. et al. Perovskite-based hybrid solar cells exceeding $10 \%$ efficiency with high reproducibility using a thin film sandwich approach. Adv. Mater. 26, 2041-2046 (2013).

23. Roy, A. et al. Spectroscopic studies on quantum dots of $\mathrm{PbI}_{2}$. Spectrochim. Acta A Mol. Biomol. Spectrsc. 48, 1779-1787 (1992).

24. Moulder, J. F. et al. Handbook of X-ray Photoelectron Spectroscopy: a Reference Book of Standard Spectra for Identification and Interpretation of XPS Data (Physical Electronics Division Perkin-Elmer Corp, 1995).

25. Roldán-Carmona, C. et al. High efficiency methylammonium lead triiodide perovskite solar cells: the relevance of non-stoichiometric precursors. Energy Environ. Sci. 8, 3550-3556 (2015).

26. Yang, M. et al. Square-centimeter solution-processed planar $\mathrm{CH}_{3} \mathrm{NH}_{3} \mathrm{PbI}_{3}$ perovskite solar cells with efficiency exceeding 15\%. Adv. Mater. 27, 6363-6370 (2015).

27. Cao, D. H. et al. Remnant $\mathrm{PbI}_{2}$, an unforeseen necessity in high-efficiency hybrid perovskite-based solar cells? APL Mater. 2, 091101-091107 (2014).

28. Lee, M. M. et al. Efficient hybrid solar cells based on meso-superstructured organometal halide perovskites. Science 338, 643-647 (2012).

29. Wozny, S. et al. Controlled humidity study on the formation of higher efficiency formamidinium lead triiodide-based solar cells. Chem. Mater. 27, 4814-4820 (2015).

30. Jiang, S.-D. et al. Fabrication of hydroxyapatite hierarchical hollow microspheres and potential application in water treatment. J. Phys. Chem. C. 116, 4484-4492 (2012).

31. Jeon, N. J. et al. Solvent engineering for high-performance inorganic-organic hybrid perovskite solar cells. Nat. Mater. 13, 897-903 (2014).

\section{Acknowledgements}

This work was financially supported by the Global Frontier R\&D Program of the Center for Multiscale Energy System (NRF-2012M3A6A7054855). The work was also supported by the National Research Foundation of Korea (NRF), funded by the Ministry of Education, Science and Technology (NRF-2012M3A7B4049967 and NRF-2014R1A4A1008474). The work at the National Renewable Energy Laboratory was supported by the U.S. Department of Energy under Contract No. DE-AC36-08-GO28308.

\section{Author contributions}

B.J.K. and D.H.K. performed the device fabrication, characterization and analysis. S.L.K., Z.L. and K.Z. prepared the samples and synthesized the perovskite materials. S.Y.P. synthesized the hydroxyapatite and performed the lead-removal processing. All authors discussed the results and prepared the manuscript. H.S.J. planned and supervised the project.

\section{Additional information}

Supplementary Information accompanies this paper at http://www.nature.com/ naturecommunications

Competing financial interests: The authors declare no competing financial interests.

Reprints and permission information is available online at http://npg.nature.com/ reprintsandpermissions.

How to cite this article: Kim, B.J. et al. Selective dissolution of halide perovskites as a step towards recycling solar cells. Nat. Commun. 7:11735 doi: 10.1038/ncomms11735 (2016).

This work is licensed under a Creative Commons Attribution 4.0 International License. The images or other third party material in this article are included in the article's Creative Commons license, unless indicated otherwise in the credit line; if the material is not included under the Creative Commons license, users will need to obtain permission from the license holder to reproduce the material. To view a copy of this license, visit http://creativecommons.org/licenses/by/4.0/ 